\title{
THE INTRAFAMILIAL TRANSMISSION OF RHEUMATOID ARTHRITIS-III
}

\section{THE LACK OF SUPPORT FOR A GENETIC HYPOTHESIS}

\author{
William J. Schull, Ph.D. and Sidney Cobb, M.D., M.P.H. \\ Department of Human Genetics and Survey Research Center, The University of \\ Michigan, Ann Arbor, Michigan
}

(Received 21 December 1967; in revised form 26 August 1968; further revised 6 January 1969)

EVER since the days of William Heberden [1], it has been commonly held that there exists an appreciable genetic component in the etiology of rheumatoid arthritis [1-4]. However, a recent review of the subject [5] concludes "With improved technics in the design and execution of family studies the evidence for familial aggregation has become less impressive and is, in fact, open to question". Another [6] concludes ". . . the available studies give little support to any genetic cause of RA". On the other hand, LAWRENCE [7] is impressed by some familial aggregation of severe disease which is not apparent for the milder cases. The present investigation was designed to measure the prevalence of rheumatoid arthritis among several classes of relatives, biological and marital, of rheumatoid probands; the latter were selected in such manner as to encompass a larger segment of the gradient of the disease than is generally studied on the assumption that thereby the "true" state of affairs might be revealed. It is our purpose now to examine the data in hand to see if they conform to any of the simpler genetic hypotheses, and if not, to ascertain the possible magnitude of the genetic contribution in more general terms.

The design of the study as well as the method of measuring rheumatoid arthritis, referred to as the RA measure, with its validation, its sensitivity ( 86 per cent), and its specificity ( 98 per cent) have been described in the first 2 papers of this series. Forty-nine family clusters are involved with members distributed as follows:

$\begin{array}{ll}\text { Key persons or probands } & 49 \\ \text { Spouses of key persons } & 49 \\ \text { Siblings } & 48 \\ \text { Spouses of siblings } & 49 \\ \text { Cousins } & 83 \\ \text { Unrelated persons } & 46\end{array}$

Six of the 49 key persons proved on final analysis not to have rheumatoid arthritis. 
In all 66 cases of RA were ascertained of which 43 are key persons and 23 occur among other members of the clusters. The ages, sexes, and the relationships to the key persons of these cases are to be found in the appendix. Table 1 presents the

TABLE 1. RA BY RELATIONSHIP TO A KEY PERSON WITH RA

\begin{tabular}{llccc}
\hline & & \multicolumn{2}{c}{ RA over total persons } & $\begin{array}{c}\text { Prevalence of RA } \\
\text { per 100 adjusted } \\
\text { for sex }\end{array}$ \\
\cline { 2 - 4 } & Males & Females & 7 \\
\hline 1. Siblings & $1 / 22$ & $2 / 20$ & 9 \\
2. Cousins & $1 / 32$ & $6 / 39$ & 8 \\
3. Spouses of key persons & $2 / 31$ & $1 / 12$ & 8 \\
4. Spouses of siblings & $0 / 20$ & $5 / 23$ & 9 \\
5. Unrelated persons & $1 / 30$ & $2 / 16$ & \\
6. Related to key person with no RA & $0 / 19$ & $2 / 11$ & \\
\hline & Total & $5 / 154$ & $18 / 121$ & \\
\hline
\end{tabular}

principal findings. The somewhat greater than usual frequency of affected females as contrasted with affected males has been previously commented upon and probably reflects the difficulty in excluding ankylosing spondylitis without excluding too much rheumatoid arthritis with back pain (see the second paper in this series).

On genetic grounds, one expects the siblings of the key persons to have more disease than the cousins, and the latter to have more than unrelated persons. The extent of the added frequency of disease will, of course, depend upon the mode of inheritance. Even the most cursory inspection of the data in Table 1 fails, however, to disclose an increase in the prevalence of RA in siblings and cousins consonant with any of the simpler modes of inheritance. In fact, when viewed in terms of prevalence per 100 individuals adjusted for sex, the frequency of the disease appears to be inversely related, albeit weakly, to biological relationship to the key person. This impression stems in part from an inordinately high occurrence of RA among the spouses of siblings of key persons, a point to which we shall return.

Though it seems most unlikely that within these data RA is distributed in accord with any of the several simpler modes of inheritance, it is still appropriate to ask what might the magnitude of the genetic contribution to this disease be. Falconfre [8] has devised a means whereby one can estimate the inheritance of liability to various diseases from the prevalence (better from the incidence) of these diseases among relatives, granted certain distributions of the liabilities. The parameter estimated is heritability which may be loosely interpreted as a measure of the genetic contribution to the etiology of the disease in question. Falconer's method, as appropriate to the present case, involves contrasting the prevalence of RA in the general population, represented by the sample of individuals not related to a key person with RA, with the prevalence in some particular class of relatives of the key persons. Since observations on 2 classes of relatives exist, namely, siblings and cousins, two heritability estimates can be calculated. We have, because of the differences between the sexes in the prevalence of RA, estimated heritability within sexes for each class of relatives. The estimates within sexes have been combined to produce a weighted mean heritability by weighting the individual estimates 
by the inverses of their variances. The variances of these weighted means are taken to be the inverses of the sums of weights. The heritability estimates with their variances are $8.0 \pm 38.2$ and $37.1 \pm 34.2$ for siblings and cousins, respectively. It should be noted that neither of these estimates, which are, of course, not independent of one another, is significantly different from zero. Thus, on the basis of these data, one is not justified in presuming that one's genetic constitution plays a significant role in the occurrence of RA. It is also apparent from the variances, however, that a substantial contribution, say 30-50 per cent, could pass undetected because of the limited nature of the observations.

This material can be examined in various other ways including weighting the RA persons by the severity of their disease, but the results are essentially the same no matter how one does the analysis. However, the numbers here are so small that any conclusion must of necessity be tenuous.

\section{DISCUSSION}

The only group that seems appreciably different from the others in Table 1 is the spouses of the siblings of the probands or more specifically the wives of the brothers of the probands. The best guess is that this is merely random variation, particularly when one notes that one of the cases is married to a man with RA and so might be considered to belong in the group of spouses.

The conclusion of no evidence for clustering in blood relatives is accompanied by evidence discoverable from the appendix and, to be discussed in the seventh paper of this series, that there is also no evidence of clustering in marital pairs. These points lead to the conclusion that heredity does not play a major role in the etiology of rheumatoid arthritis. This supports the modern trend of thought in this area $[5,6,9]$.

At this point, one might ask if there are faults in earlier studies that might have led to a conclusion of clustering in families when, in fact, none existed. A number of explanations for a spurious familial aggregation of disease suggest themselves. First, there exists the possibility of a reporting bias wherein a person with rheumatoid arthritis is more likely to report arthritis in his or her relatives than a person not so affected. In the material of this study we are able to look for such bias, and the evidence for its existence is given in Table 2. In the upper part of the table, it is shown that in those instances where no second report on the parents is available one would conclude that there is a very large excess of arthritis in the parents of those who are positive on the RA measure. However, from the lower portion of the table, we see that when we have both RA and not-RA siblings reporting on the same parents, the difference between their reports is nearly as great as that noted above. A similar but more limited mail inquiry of the siblings of our key persons located 18 individuals with arthritis on whom we were able to get reports from arthritic and non-arthritic siblings. An arthritic sibling was defined as one who responded positively in the mail questionnaire to the 3 questions of the RA index [10]. The arthritic siblings identified 7 of the 18 while the non-arthritic identified only 4. Errors of this nature may have exaggerated the extent of the family clustering in the early studies which were patient centered.

Second, biases in the selection of study families could result in a spurious aggregation of affected individuals. It should be intuitively obvious that if families are 
TABLE 2. REPORTING OF ARTHRITIS IN PARENTS BY PERSONS RA POSITIVE AND RA NEGATIVE

A. Persons RA and $\overline{\mathbf{R A}}$ compared

\begin{tabular}{|c|c|c|}
\hline \multirow[b]{2}{*}{$\begin{array}{l}N \\
\text { Percentage reporting neither parent with arthritis } \\
\text { Percentage reporting one parent with arthritis } \\
\text { Percentage reporting both parents with arthritis }\end{array}$} & \\
\hline & $\begin{array}{c}\text { RA measure } \\
\text { positive } \\
19 \\
16 \\
53 \\
31\end{array}$ & $\begin{array}{c}\text { RA measure } \\
\text { negative } \\
201 \\
55 \\
37 \\
8\end{array}$ \\
\hline & 100 & 100 \\
\hline
\end{tabular}

B. Two siblings reporting on the same parent

\section{$N$}

Percentage reporting neither parent with arthritis Percentage reporting one parent with arthritis Percentage reporting both parents with arthritis
Sibling reporting

\begin{tabular}{cc}
\hline $\begin{array}{c}\text { RA measure } \\
\text { positive }\end{array}$ & $\begin{array}{c}\text { RA measure } \\
\text { negative }\end{array}$ \\
40 & 40 \\
27 & 50 \\
58 & 42 \\
15 & 8 \\
\hline 100 & 100
\end{tabular}

100

Note: $19+201+40+40=310$. There were 14 persons whose information about their parents was incomplete.

selected for study through the occurrence of an affected individual in the family, and if the latter such individuals are not exhaustively sampled, the probability that a given family will be selected will, in the limit, be proportional to the number of affected individuals. Thus, families with large numbers of affected individuals will be disproportionately represented in the sample. Few if any studies have made allowance for this error which under some circumstances can be appreciable and in most can be difficult to estimate [11]. We have not adjusted for the sampling method here because the siblings can be compared with spouses of the key persons without fear of serious bias and because there is no evidence of an excess frequency of RA among sibs which might have been caused by this error.

The third error that may have led to exaggeration of the familial clustering in previous studies is the fact that persons with arthritis have a greater tendency to participatc in a study of arthritis than do those with no arthritis [12]. By itself, this can cause a spurious reduction of the frequency of unaffected sibships in a population study. It is also possible that arthritic persons with relatives with arthritis are more likely to participate in a family study of arthritis, but at present there are no data relevant to this point.

Fourth, it might be charged that persons with arthritis who watched their parents suffer with arthritis might be more likely to seek medical care. This does not, however, appear to be true. Similarly, the notion that persons with arthritis dislike change and might, therefore, be found closer to their parental home than their siblings, as suggested in an earlier publication [9], has not been adequately documented.

Finally, if we assume that the earlier studies did, in fact, overestimate whatever 
genetic effect there may be, the error has, perhaps, been compounded by authors and cditors who have failed to publish negative studies.

Since there appears to be no evidence of clustering, is there any reason to proceed with psychological and social hypotheses about the familial contribution to rheumatoid arthritis? One's inclination is to say 'no' but on reflection the absence of even random aggregation suggests certain models, e.g. the scapegoat, which are testable. Some families practice scapegoating and others do not, but there is very seldom more than 1 scapegoat per family. With this thought in mind, it has seemed worthwhile to pursue characteristics of the family of origin and see if they related to the frequency of RA. The results of this approach are to be presented in subsequent papers.

\section{SUMMARY}

This report does not support a conclusion that heredity is an important feature of the etiology of rheumatoid arthritis. Errors that might have contributed to earlier conclusions have been discussed.

\section{REFERENCES}

1. Heberden, W.: Commentaries on the History and Cure of Diseases, 3rd Ed. Payne, London, 1806.

2. GARROD, A. E.: A Treatise on Rheumatism and Rheumatoid Arthritis. Griffin, London, 1890.

3. Stecher, R. M., Hirsh, A., Solomon, W. M. and Wolpaw, R.: The genetics of rheumatoid arthritis: analysis of 224 families. Am. J. hum. Genet. 5, 118, 1953.

4. Kellgren, J. H.: Heberden Oration 1963. Ann. rheum. Dis. 23, 109, 1964.

5. MASI, A. I. and Sirulman, L. E.: Familial aggregation and rheumatoid disease. Arthritis Rheum. 8, 418, 1965.

6. O'BrIEN, W. M.: The genetics of rheumatoid arthritis. Clin. exp. Immunol. 2 Suppl., 785, 1967.

7. LAWRENCE, J. S.: Genetics of rheumatoid factor and rheumatoid arthritis. Clin. exp. Immunol. 2 Suppl., 769, 1967.

8. FALCONER, D. S.: The inheritance of liability to certain diseases, estimated from the incidence among relatives. Ann. hum. Genet. 29, 51, 1965.

9. Cовв, S.: The epidemiology of rheumatoid arthritis. Arthritis Rheum. 8, 76, 1965.

10. Rubin, T., Rosenbaum, J. and CoBb, S.: The use of interview data for the detection of associations in field studies. J. chron. Dis. 4, 253, 1956.

11. Crow, J. F.: Problems of ascertainment in the analysis of family data. In: Genetics and the Epidemiology of Chronic Diseases (Eds. NeEL, J. V., SHAW, M. W. and Schull, W. J.) Washington, D.C. U.S. Government Printing Office, 1965.

12. Corb, S., King, S. and C.HFN, F.: Differences between respondents and non-respondents in a morbidity survey involving clinical examination. J. chron. Dis. 6, 95, 1957. 


\section{APPENDIX}

AGE, SEX, AND RA FOUR-POINT SCALE IN THE CLUSTERS

\begin{tabular}{|c|c|c|c|c|c|c|c|}
\hline $\begin{array}{l}\text { Cluster } \\
\text { number }\end{array}$ & K.P. & $\begin{array}{l}\text { KP's } \\
\text { spouse }\end{array}$ & Sib & $\begin{array}{l}\text { Sib’s } \\
\text { spouse }\end{array}$ & $\begin{array}{c}\text { Paternal } \\
\text { cousin }\end{array}$ & $\begin{array}{l}\text { Maternal } \\
\text { cousin }\end{array}$ & Unrelated \\
\hline 025 & $63, F, 3$ & $65, M, 3$ & $64, M, 0$ & $53, \mathrm{~F}, 0$ & $62, F, 0$ & $64, M, 0$ & $60, \mathrm{M}, 0$ \\
\hline 126 & $47, F, 3$ & $48, M, 0$ & $49, M, 0$ & $51, \mathbf{F}, 0$ & - & - & $46, \mathrm{M}, 0$ \\
\hline 129 & $29, F, 3$ & $35, M, 1$ & $35, F, 0$ & $51, \mathrm{M}, 0$ & $40, \mathrm{M} \mathrm{O}$ & $32, F, 1$ & $36, \mathrm{M}, 0$ \\
\hline 136 & 43.F,3 & $51, \mathrm{M}, 0$ & $50, \mathrm{~F}, 0$ & $49, \mathbf{M}, 1$ & - & $50, \mathrm{~F}, 0$ & $50, \mathbf{M}, 0$ \\
\hline 146 & $32, F, 3$ & $34, M, 0$ & $28, M, 0$ & $26, F, 2$ & $33, M, 0$ & $30, F, 0$ & $35, M, 1$ \\
\hline 147 & $57, F, 3$ & $52, \mathrm{M}, 0$ & - & $52, \mathrm{~F}, 0$ & - & $50, \mathrm{M}, 0$ & $52, \mathrm{M}, 0$ \\
\hline 179 & $46, F, 3$ & $48, M, 0$ & $48, \mathrm{M}, 0$ & $44, F, 0$ & $41, M, 0$ & $47, \mathrm{~F}, 0$ & $48, \mathrm{M}, 0$ \\
\hline 180 & $52, F, 3$ & $52, \mathrm{M}, 3$ & $51, \mathrm{M}, 0$ & $55, F, 3$ & $56, \mathbf{M}, 0$ & - & $53, M, 0$ \\
\hline 181 & $58, F, 3$ & $61, M, 0$ & $65, \mathrm{M}, 0$ & $64, F, 0$ & $57, \mathrm{M}, 0$ & $55, \mathrm{M}, 2$ & $62, M, 0$ \\
\hline 182 & $55, \mathrm{M}, 3$ & $55 . F, 0$ & $57, \mathrm{~F}, 0$ & $58, \mathrm{M}, 0$ & $56, F, 0$ & - & $50, \mathrm{~F}, 0$ \\
\hline 183 & $35, F, 3$ & $37, \mathbf{M}, \mathbf{0}$ & $38, M, 0$ & $39, F, 0$ & - & $39, F, 0$ & $37, \mathrm{M}, 0$ \\
\hline 184 & $54, F, 3$ & $61, M, 0$ & $57, F, 0$ & $55, \mathrm{M}, 0$ & $61 . F, 0$ & $63, \mathrm{M}, 0$ & $65, M, 1$ \\
\hline 187 & $56, \mathrm{M}, 3$ & $50, F, 0$ & $48, F, 0$ & $57, \mathbf{M}, 0$ & $52, \mathrm{M}, 0$ & $54, \mathrm{~F}, 0$ & $49, \mathrm{~F}, 0$ \\
\hline 188 & $50, \mathrm{~F}, 3$ & $51, \mathrm{M}, 0$ & $52, \mathrm{M}, 0$ & $44, F, 0$ & $49, \mathrm{~F}, \mathrm{0}$ & $50, \mathrm{~F}, 0$ & $53, \mathbf{M}, 0$ \\
\hline 189 & $44, F, 3$ & $48, \mathrm{M}, \mathbf{0}$ & $49, F, 0$ & $54, \mathrm{M}, 0$ & $49, F, 0$ & $45, F, 0$ & $44, \mathrm{M}, 0$ \\
\hline 191 & $53, M, 3$ & $52, F, 0$ & $51 . F, 3$ & $66, M, 0$ & $51, \mathbf{M}, \mathbf{0}$ & $54, F, 0$ & $49, F, 0$ \\
\hline 193 & $30, F, 3$ & 33,M,0 & $38, \mathrm{M}, 0$ & $40, F, 0$ & $36, \mathrm{M}, 0$ & 34.M, 0 & $30, \mathrm{M}, 0$ \\
\hline 194 & $48, F, 3$ & $44, \mathrm{M}, \mathbf{0}$ & $45, \mathrm{M}, 2$ & $42, F, 3$ & $47, \mathrm{M}, 0$ & $44, F, 0$ & $38, \mathrm{M}, 0$ \\
\hline 195 & $51, \mathrm{M}, 3$ & $46, F, 1$ & $41, F, 0$ & $39, \mathrm{M}, 0$ & $50, \mathrm{M}, 0$ & $44, F, 0$ & $51, F, 0$ \\
\hline 196 & $61, M, 3$ & $57, F, 0$ & $59, \mathrm{~F}, 0$ & $63, \mathrm{M}, 0$ & $57, \mathrm{M}, 0$ & $51, \mathrm{~F} 0$ & $53, \mathrm{~F}, 0$ \\
\hline 197 & $39, F, 3$ & $40, \mathrm{M}, 0$ & $41, F, 0$ & $47, \mathrm{M}, 0$ & - & $44, \mathrm{M}, 0$ & $35, \mathrm{M}, 0$ \\
\hline 198 & $59, \mathrm{M}, 3$ & $55, F, 0$ & $54, \mathrm{M}, 0$ & $51, F, 0$ & $50, \mathrm{M}, 0$ & $59, F, 2$ & - \\
\hline 199 & $44, M, 3$ & $41, F, 0$ & $46, M, 0$ & $45, F, 0$ & $47, \mathrm{M}, 0$ & $47, \mathrm{M}, 0$ & $43, F, 2$ \\
\hline 200 & $55, \mathrm{M}, 3$ & $51, \mathbf{F}, 0$ & $57, \mathrm{M}, 0$ & $56, \mathrm{~F}, 0$ & $51, F, 0$ & $52, \mathrm{M}, 0$ & $52, \mathrm{~F}, 0$ \\
\hline 203 & $59, \mathrm{~F}, 3$ & $60, M, 0$ & $57, \mathrm{~F}, 0$ & $58, \mathrm{M}, 0$ & $58, F, 2$ & $60, F, 3$ & $60, M, 0$ \\
\hline 204 & $55, \mathrm{M}, 3$ & $53, F, 0$ & $49, F, 0$ & $50, \mathrm{M}, 0$ & $49, \mathrm{M}, 0$ & - & $54, F, 0$ \\
\hline 004 & $31, F, 2$ & $35, \mathbf{M}, 0$ & $33, \mathrm{M}, 0$ & $34, F, 0$ & $33, F, 0$ & $32, F, 0$ & $38, \mathrm{M}, 0$ \\
\hline 006 & $43, F, 2$ & 47,M,0 & $40, M, 0$ & $29, F, 0$ & - & $44, M, 0$ & $45, \mathrm{M}, 0$ \\
\hline 014 & $58, \mathrm{~F}, 2$ & $60, M, 0$ & $54, \mathrm{M}, 0$ & $51, \mathrm{~F}, 0$ & $61, F, 0$ & $59, \mathrm{~F}, 2$ & - \\
\hline 026 & $47, F, 2$ & $45, \mathrm{M}, 0$ & $40, F, 0$ & $44, \mathrm{M}, 0$ & $46, F, 0$ & $40, \mathrm{M}, 0$ & $46, \mathrm{M}, 0$ \\
\hline 038 & $72, F, 2$ & $71, \mathrm{M}, 0$ & $70, \mathbf{M}, 0$ & $67, \mathrm{~F}, 3$ & $76, F, 0$ & $72, F, 3$ & $72, \mathrm{M}, 0$ \\
\hline 043 & $69, F, 2$ & $74, M, 0$ & $72, F, 0$ & $80, \mathrm{M}, 0$ & $75, F, 0$ & - & $72, \mathrm{M}, 0$ \\
\hline 050 & $51, \mathrm{M}, 2$ & $47, F, 0$ & $44, F, 0$ & $49, \mathrm{M}, 0$ & $47, \mathrm{~F}, 0$ & $40, \mathrm{M}, 0$ & $47, \mathrm{~F}, 1$ \\
\hline 066 & $51, F, 2$ & 50,M,0 & $56, \mathrm{~F}, 2$ & $68, \mathrm{M}, 0$ & $52, \mathrm{~F}, 0$ & $49, \mathrm{~F}, 0$ & 49,M,0 \\
\hline 075 & $32, F, 2$ & $36, M, 0$ & $38, F, 0$ & $42, M, 0$ & $37, F, 0$ & $37, F, 0$ & $41, \mathrm{M}, 0$ \\
\hline 077 & $54, F, 2$ & $55, \mathrm{M}, 0$ & $52, \mathrm{M}, 0$ & $41, F, 1$ & - & $56, \mathrm{~F}, 0$ & $55, \mathrm{M}, 0$ \\
\hline 091 & $31, F, 2$ & $41, \mathbf{M}, 0$ & $34, \mathrm{M}, 0$ & $31, F, 0$ & $30, F, 0$ & $35, \mathrm{M}, 0$ & $29, \mathbf{M}, 0$ \\
\hline 111 & $46, F, 2$ & $46, \mathrm{M}, 0$ & $44, \mathrm{M}, 0$ & $41, \mathrm{~F}, 0$ & - & $44, \mathrm{M}, 0$ & $49, \mathrm{M}, 1$ \\
\hline 116 & $55, F, 2$ & $55, M, 0$ & $52, F, 0$ & $58, \mathrm{M}, 0$ & $54, F, 0$ & $54, \mathrm{M}, 0$ & $59, \mathrm{M}, 0$ \\
\hline 143 & $55, \mathrm{M}, 2$ & $49, F, 1$ & $50, F, 0$ & $55, \mathrm{M}, 0$ & $48, \mathrm{M}, 0$ & & $54, F, 2$ \\
\hline 150 & $28, F, 2$ & $32, \mathrm{M}, 0$ & $26, F, 0$ & $29, \mathrm{M}, 0$ & $33, F, 1$ & $29, \mathrm{M}, 0$ & $29, \mathrm{M}, 0$ \\
\hline 177 & 61,M,2 & $60, F, 3$ & $63, \mathrm{M}, 0$ & $58, \mathrm{~F}, 0$ & $60, M, 0$ & - & $58, F, 0$ \\
\hline 205 & $44, F, 2$ & $47, \mathrm{M}, 0$ & $43, \mathbf{M}, 0$ & $41, F, 2$ & $44, M, 0$ & $40, F, 3$ & - \\
\hline 003 & 73,M,1 & $72, F, 0$ & $71, \mathbf{M}, 0$ & $77, F, 3$ & $68, F, 0$ & $71, F, 0$ & $70, F, 0$ \\
\hline 011 & $59, M, 0$ & $50, F, 0$ & $47, \mathrm{M}, 0$ & $42, \mathrm{~F}, 0$ & $49, F, 2$ & $55, \mathbf{M}, 0$ & $44, F, 0$ \\
\hline 094 & $40, \mathrm{M}, 0$ & $36, F, 0$ & $35, F, 0$ & $47, \mathrm{M}, 0$ & $34, \mathrm{M}, 0$ & $36, M, 0$ & $39, \mathrm{~F}, 0$ \\
\hline 104 & $60, F, 0$ & $58, \mathrm{M}, 0$ & $59, \mathrm{M}, 0$ & $53, F, 0$ & $58, \mathrm{M}, 0$ & $64, M, 0$ & $54, \mathrm{M}, \mathrm{n}$ \\
\hline 124 & $61, F, 0$ & $63, \mathrm{M}, 0$ & $64, F, 0$ & $68, \mathrm{M}, 0$ & $58, \mathrm{M}, 0$ & $65, \mathrm{M}, 0$ & $62, \mathrm{M}, 2$ \\
\hline 178 & $51, \mathrm{~F}, 0$ & 49,M,0 & $49, F, 0$ & $44, M, 0$ & $48, M, 0$ & $48, F, 0$ & 46,M.0 \\
\hline
\end{tabular}

Note: National sample clusters have numbers less than 179. Clinic sample clusters have numbers 179 and over. 